\title{
INVESTIGATION OF CONTROL OPPORTUNITIES FOR THERMAL PERFORMANCE OF THE PERIPHERAL ZONE OF BLAST FURNACE
}

\author{
Jimoh S.O., Postgraduate (sma i la20002001@yahoo.co.uk) \\ Lozovich A.V., master degree student \\ Zagainov S.A., Dr. Sci. (Eng.), Prof., Head of the Chair
}

Ural Federal University named after the first President of Russia Yeltsin B.N. (Mira str., 19, Ekaterinburg, 620002, Russia)

Abstract. High content of $\mathrm{FeO}$ in primary slag prevents formation of stable skull thereby increasing the thermal load on the fridges and heat losses. Development of indirect reduction reactions that determine the $\mathrm{FeO}$ content in primary slag depends on heat transfer conditions. The purpose of this research was to develop methods of modeling of heat transfer in the peripheral zone of blast furnace. The model was developed using the laws of heat transfer and gas dynamics. It allows to estimate the influence of ore load, size distribution of iron materials on development of heat transfer processes and recovery work of the gas flow in blast furnace.
Keywords: blast furnace, peripheral zone, heat transfer, ore load, indirect reduction.

\section{REFERENCES}

1. Balon I.D. etc. Domennoe proizvodstvo [Blast-furnace ironmaking]. Vol. 1. Vegman E.F. ed. Moscow: Metallurgiya, 1989. 495 p. (In Russ.).

2. Kitaev B.I., Yaroshenko Yu.G., Sukhanov E.L. etc. Teplotekhnika domennogo protsessa [Heat engineering of blast-furnace process]. Moscow: Metallurgiya, 1978. 248 p. (In Russ.).

3. Jimoh S.O., Pyhteeva C.B, Zagaynov S.A. Analysis of the characteristics of the blast furnace peripheral zone. International journal of scientific \& technology research. 2013. Vol. 2, Issue 9, pp. $125-128$.

Received March 21, 2014

\section{ДИФФУЗИОННОЕ ТИТАНОАЛЮМОСИЛИЦИРОВАНИЕ СТАЛИ 12Х18Н10Т В ПОРОШКАХ ПРИ ПОНИЖЕННОМ ДАВЛЕНИИ}

\author{
Хижнняк В.Г., д.т.н., профессор кафедры металловедения и термической обработки \\ Ариук М.В., ассистент кафедры металловедения и термической обработки (mar ina351@rambler.ru)
}

Дацюк О.Э., аспирант кафедры металловедения и термической обработки

Национальный технический университет Украины «Киевский политехнический институт»

(03056, Украина, Киев, пр. Победы, 37)

\begin{abstract}
Аннотация. Исследованы фазовый и химический составы, структура и микротвердость диффузионных многослойных покрытий, содержащих титан, алюминий и кремний на образцах из стали 12Х18Н10Т. Установлено, что в процессе химико-термической обработки образуются покрытия на основе интерметалидов, карбида и нитрида титана, а также твердый раствор титана, алюминия, кремния никеля, хрома в аустените основы.
\end{abstract}

Ключевые слова: сталь 12Х18Н10Т, титан, алюминий, кремний, диффузионные покрытия.

Научный и практический интерес представляет химико-термическая обработка стали $12 \mathrm{X} 18 \mathrm{H} 10 \mathrm{~T}$, в результате которой появляется возможность получения нового материала, сочетающего высокие свойства основы и диффузионной зоны.

Анализ свойств известных многокомпонентных покрытий на металлах и сплавах $[1,2]$ показал целесообразность получения на стали $12 \mathrm{X} 18 \mathrm{H} 10 \mathrm{~T}$ слоев с участием титана, алюминия, кремния со свойствами, более высокими, чем после однокомпонентного насыщения титаном, алюминием, кремнием. Научно-техническая информация относительно строения и свойств многокомпонентных покрытий после совместного насыщения стали $12 \mathrm{X} 18 \mathrm{H} 10$ Т титаном, алюминием, кремнием носит неполный характер $[1,2]$. Таким образом, целью настоящей работы было получение на стали $12 \mathrm{X} 18 \mathrm{H} 10 \mathrm{~T}$ многокомпонентных покрытий, исследование их фазового и химического составов, структуры и микротвердости.

Покрытия наносили при пониженном давлении в порошковой смеси следующего состава: $30 \% \mathrm{Ti}+15 \% \mathrm{Al}+$ $+15 \% \mathrm{Si}+4 \% \mathrm{NH}_{4} \mathrm{Cl}+36 \% \mathrm{Al}_{2} \mathrm{O}_{3}$. Полученные таким образом покрытия были изучены рентгеноструктурным, микрорентгеноспектральным, микроструктурным и дюрометрическим методами.

Послойным рентгеноструктурным анализом установлено существование в диффузионном слое двух зон: зоны соединений и переходной зоны (см. таблицу). В зоне соединений от поверхности к основе 


\section{Условия насыщения, фазовый состав и свойства титаноалюмосилицированного покрытия на стали 12Х18Н10Т}

\begin{tabular}{|c|c|c|c|c|}
\hline $\begin{array}{c}\text { Вид ХТО и режим: } T,{ }^{\circ} \mathrm{C} ; \\
\tau \text { (время насыщения), ч }\end{array}$ & Фазовый состав & $\begin{array}{c}\text { Параметр кристаллической } \\
\text { решетки, нм }\end{array}$ & $\begin{array}{c}\text { Толщина слоя, } \\
\text { мкм } \\
\end{array}$ & $\begin{array}{l}\text { Микротвердость, } \\
\text { ГПа }\end{array}$ \\
\hline \multirow{7}{*}{$\begin{array}{c}\text { Титаноалюмосилицирование: } \\
1050 ; 4\end{array}$} & \multirow{2}{*}{$\mathrm{Ti}_{3} \mathrm{Al}$} & $\mathrm{a}=0,5812$ & \multirow{2}{*}{$2,5-3,0$} & \multirow{2}{*}{-} \\
\hline & & $\mathrm{c}=0,4664$ & & \\
\hline & $\mathrm{FeTi}$ & $a=0,2988$ & $3,5-4,5$ & 5,0 \\
\hline & \multirow{2}{*}{$\mathrm{Fe}_{2} \mathrm{Ti}$} & $a=0,4830$ & \multirow{2}{*}{$10,5-11,5$} & \multirow{2}{*}{$6,5-7,0$} \\
\hline & & $\mathrm{c}=0,7846$ & & \\
\hline & $\operatorname{Ti}(\mathrm{C}, \mathrm{N}, \mathrm{O})$ & $a=0,4316$ & $1,0-2,0$ & 28,5 \\
\hline & Переходная зона & $a=0,2888$ & $32,0-34,0$ & $4,0-2,2$ \\
\hline
\end{tabular}

располагаются следующие слои: $\mathrm{Ti}_{3} \mathrm{Al}, \mathrm{FeTi}, \mathrm{Fe}_{2} \mathrm{Ti}$, $\mathrm{Ti}(\mathrm{C}, \mathrm{N}, \mathrm{O})$. Непосредственно к основе примыкает переходная зона - твердый раствор насыщающих элементов (титан, алюминий, кремний) и элементов основы (никель, хром) в феррите. Образование в процессе химико-термической обработки слоя феррита происходит в результате достижения предельной концентрации в аустените титана, алюминия, кремния и протекания полиморфного превращения $\mathrm{Fe}_{\gamma} \rightarrow \mathrm{Fe}_{\alpha}$. Период кристаллической решетки легированного феррита переходной зоны оказывается выше, чем нелегированного. Это обусловлено значительным содержанием в нем таких элементов, как титан, алюминий, кремний, атомные размеры которых выше атомных размеров железа (см. рисунок).

В микроструктуре покрытий после легкого травления реактивом Марбля были выявлены и установлены рентгеноструктурным методом светло- или темно-серые интерметаллидные фазы в зоне соединений. Их слои разделены хорошо выраженными границами в виде прямых линий, параллельных поверхности.

Максимальная микротвердость полученных покрытий $(5,0-28,5$ ГПа) была установлена для зоны соединений. Микротвердость переходной зоны непосред-
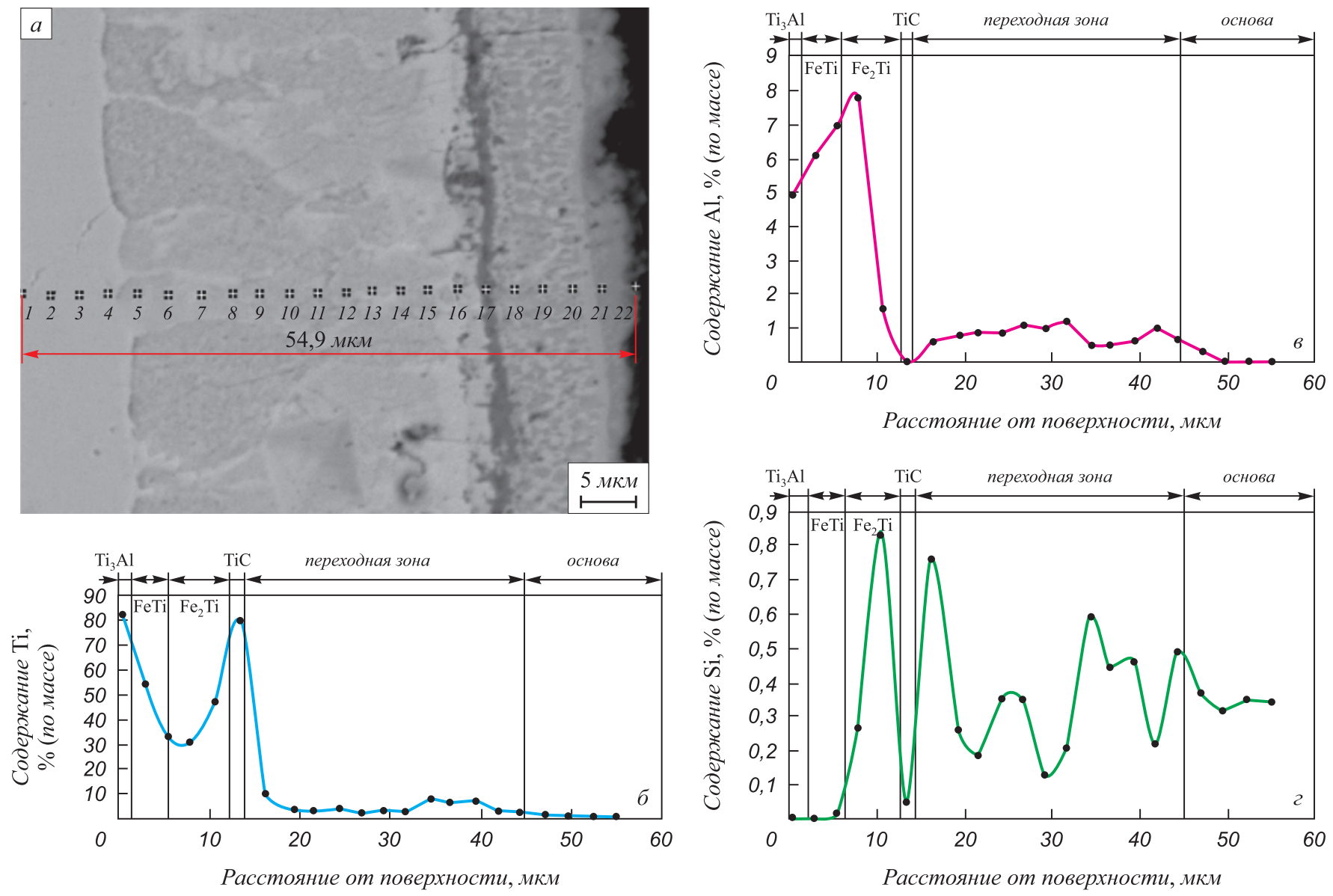

Микроструктура титаноалюмосилицированной стали 12X18Н10Т (a) и распределение элементов по толщине покрытия: $\mathrm{Ti}($ ()); $\mathrm{Al}($ (b); $\mathrm{Si}(2)$ 
ственно за границей с зоной соединений составляла 3,5 - 4,2 ГПа и плавно уменьшалась до микротвердости основы.

Можно считать, что полученные и исследованные в работе покрытия на стали $12 \mathrm{X} 18 \mathrm{H} 10 \mathrm{~T}$ по фазовому и химическому составам, структуре могут оказаться перспективными при эксплуатации в условиях эрозии, действия высоких температур и агрессивных сред.

\section{БИБЛИОГРАФИЧЕСКИЙ СПИСОК}

1. Химико-термическая обработка металлов и сплавов: Справочник. / Г.В. Борисенок, Л.А. Васильев, Л.Г. Ворошнин и др. - М.: Металлургия, 1981. - 424 с.

2. Коломыцев П.Т. Жаростойкие диффузионные покрытия. - М.: Металлургия, - 1979. - 272 с.

(C) 2014 г. Хижняк В.Г., Аршук М.В., Дачюк О.Э. Поступила 30 апреля 2014 г.

Izvestiya VuZov. Chernaya Metallurgiya = Izvestiya - Ferrous Metallurgy. 2014. No. 7. Vol. 57, pp. 67-69.

\section{DIFUSION POWDER Ti-AI-SILICONIZING OF STEEL 12Cr18Ni10Ti UNDER REDUCED PRESSURE}

Khizhnyak V.G., Dr. Sci. (Eng.), Professor of the Chair of Material Science and Heat treatment

Arshuk M.V., Postgraduate of the Chair of Material Science and Heat treatment (marina351@rambler.ru)

Datsyuk O.E., Postgraduate

Kiev Polytechnic Institute, (Pobedy pr., 37, Kiev, 03056, Ukraine)

Abstract. The phase and chemical composition, structure and microhardness, diffusion of multilayer coatings containing titanium, aluminum and silicon were examined at samples of steel $12 \mathrm{Cr} 18 \mathrm{Ni10Ti}$. It was established that the coating was formed on the basis of intermetallic compounds, carbides and titanium nitrides, as well as a solid solutions of titanium, aluminum, silicon, nickel and chromium in the austenite substrate.

Keywords: steel 12Cr18Ni10Ti, titanium, aluminum, silicon, diffusion coatings.

\section{REFERENCES}

1. Borisenok G.V., Vasil'ev L.A., Voroshnin L.G. etc. Khimiko-termicheskaya obrabotka metallov $i$ splavov [Chemical heat treatment of metals and alloys]. Moscow: Metallurgiya. 1981, 424 p. (In Russ.).

2. Kolomytsev P.T. Zharostoikie diffuzionnye pokrytiya [Heat-resistant diffusion coatings ]. Moscow: Metallurgiya. 1979, 272 p. (In Russ.). Received April 30, 2014 